\title{
Occupational Therapy Programming Facilitates Goal Attainment in a Community Work Rehabilitation Setting
}

\author{
Tina DeAngelis · Kimberly Mollo $(i) \cdot$ Carolyn Giordano • Michaela Scotten • \\ Brianna Fecondo
}

Received: 25 September 2018/Accepted: 24 December 2018/Published online: 5 January 2019

(C) The Author(s) 2019

\begin{abstract}
An occupational therapy program for participants with mental health challenges, a history of serious mental illness, recovering from substance use disorders, on parole/probation, and/or experiencing homelessness was implemented in a community work rehabilitation setting. The impact of occupational therapy interventions focused on stress and anger management, sleep hygiene, anxiety and depression management, relapse prevention for addiction, vocational and academic skill building, money management, healthy eating, and relationship and leisure skill development. Participant satisfaction and performance scores regarding individual goal setting and attainment was collected and analyzed via retrospective review of pre/post outcome scores $(n=44)$ obtained through the Canadian Occupational Performance Measure (COPM). Results indicated significant differences $(p<.05)$ from baseline to end of the program, with high effect sizes $(d=1.79-1.94)$. End of program participant satisfaction and performance scores were highly correlated $(r=.88, p<.00)$,
\end{abstract}

T. DeAngelis · K. Mollo ( ()$\cdot$ M. Scotten · B. Fecondo Department of Occupational Therapy, Thomas Jefferson University, 901 Walnut Street, 6th Floor, Philadelphia, PA 19107, USA

e-mail: kimberly.mollo@jefferson.edu

C. Giordano

Associate Provost of Institutional Effectiveness, University of the Sciences, 600 South 43rd Street, Philadelphia, PA 19104, USA indicating those who were highly satisfied reported greater performance scores. Post discharge narrative participant responses also support COPM outcomes. Findings suggest community-based occupational therapy may improve individual performance and satisfaction in daily activities while enhancing participation in tasks that are healthy and significant to the person.

\section{Introduction}

According to the World Health Organization (WHO), the number of individuals experiencing serious mental illness (SMI) continues to rise, negatively impacting many aspects of social, occupational, and economic functioning world-wide. Treatment and support from available health care and community resources remains inadequate, limiting education and employment opportunities and resulting in decreased quality of life for many individuals diagnosed with conditions such as schizophrenia, bipolar disorder, major depressive disorder, anxiety, trauma, and substance use disorder [1]. In the United States, the National Alliance on Mental Illness (NAMI) reveals that "serious mental illness costs America $\$ 193.2$ billion in lost earnings per year... and about 13.6 million live with a serious mental illness such as schizophrenia, depression, or bipolar disorder" [2, p. 1]. Additionally, for some Americans experiencing SMI, incarceration 
becomes an unintended consequence of a fragmented and over-burdened health care system ill-equipped to provide necessary services [3, 4]. After serving convictions, individuals with ex-offending histories and SMI are unprepared to navigate the barriers that impact occupational engagement, housing and employment prospects, further limiting opportunities for successful reintegration as productive members of society [5].

The occupational therapy profession, whose origins are intimately rooted in psychiatry, identifies mental health practice as a main area of refocus for the twenty-first century [6]. Occupational therapy's philosophical conviction purports that "engagement in meaningful occupation, with its intrinsic power to maintain, restore, and transform, is fundamental to the health and well-being of all humans," indicating that regular engagement in meaningful activities can uniquely and positively support society's health and wellness needs [7, p. 121] Currently, a small but growing number of occupational therapists practice in acute and outpatient psychiatric facilities, as well as community-based mental health settings to help individuals address barriers to activity engagement and employment needs resulting from SMI. Occupational therapists provide skilled support for cognitive limitations, mental health co-morbidities, and physical deficits, and work with individuals with SMI to develop meaningful habits (i.e., healthy eating and establishing an exercise routine), routines (i.e., adhering to a daily schedule and managing medications), and roles (i.e., obtaining employment, enrolling in higher education courses, acquiring parenting skills) [8]. Occupational therapy treatment aims to improve quality of life with desired daily living tasks while promoting social engagement, community reintegration, and development of normative life roles [9-15].

Individuals experiencing SMI indicate that meaningful employment is necessary to the process of recovery and affords the opportunity to live a normal and fulfilling life [16]. However, unemployment rates of 70 to $80 \%$ and inconsistent job engagement often results in financial instability and ongoing economic marginalization [17]. For those experiencing a SMI with a history of incarceration, the time required to locate and obtain gainful employment is further protracted when compared to others with SMI alone [18].
Current literature demonstrates strong efficacy for supported employment programs for individuals with SMI designed around the Individual Placement and Support (IPS) model [19-22]. Principles of IPS include competitive employment, rapid job searching, integration of rehabilitation and mental health treatments, attention to consumer work preferences, continuous and comprehensive assessment, timeunlimited support, benefits counseling, and cultivation of employer/employee relationship [9, 21]. However, evidence suggests the IPS model may not adequately address individual self-care and life skills deficits experienced by those with SMI outside of the workplace setting [9]. Findings demonstrate that using an occupational therapy approach tailoring goals and supports to each individual's direct needs can promote long-term recovery in the areas of self-reliance, responsibility, and independence. The aforementioned skills are particularly important as engaging in a variety of socially-valued and meaningful occupations has been defined as a multi-layered and evolving process by those experiencing SMI [23]. When life skills such as financial management, health maintenance, community mobility, education, and/or leisure engagement are targeted by occupational therapists treating individuals with SMI, independent functioning and community reintegration within and outside of the work environment leads to improved well-being and quality of life [9-11, 24-27]. Stetler and Whisner [28] described an occupational therapy sheltered workshop program for individuals experiencing SMI with ex-offending histories that promoted the necessary skills for community engagement and socialization and development of meaningful life roles postincarceration. Findings demonstrated increased responsibility and self-efficacy for participants in the areas of independent functioning, technical skills, performance behavior, and social skills.

Outside of the occupational therapy literature, a randomized control trial by Valencia, Rascon, Juarez, and Murow examined the impact of psychosocial skills training in the areas of social skills, budgeting, medication management and relationship building compared to the standard treatment of a monthly medication consultation with a psychiatrist [29]. Findings indicated that the intervention group revealed significant improvement pre/post measurement in the areas of symptom management, occupational, and psychosocial performance and 
demonstrated a decrease in relapse and hospital readmission. Bartels et al., also obtained similar results in a nonrandomized control trial with older adult participants with mental health diagnoses who received a combination of health management and skills training compared to those who received only health management training [30]. One-year postintervention, findings indicated that a combination of both interventions yielded a positive effect size in relation to social, daily living, and health management skills in comparison to those who received health management training only.

The following retrospective data analysis strove to analyze the efficacy of an occupational therapy-based program that enhanced community health and wellbeing for individuals with mental health challenges, a history of SMI, recovering from substance use, on parole/probation, and/or experiencing homelessness in order to support individuals to participate in life to their fullest potential. Secondary aims included determining the efficacy of occupational therapy services in order to support potential development of programming at additional behavioral health communitybased sites.

\section{Methods}

In 2013, an occupational therapy program was implemented in a Northeastern U.S. non-profit work rehabilitation organization for individuals typically underutilized and stigmatized in the traditional workforce, including those with mental health challenges, a history of SMI, recovering from substance use, on parole/probation, and/or experiencing homelessness. The program provided "real-life" minimum wage work experience as a transition step towards competitive and gainful employment for adults who experience difficulties finding jobs. A total of 18 occupational therapy students (nine pairs) and one licensed occupational therapist participated in a collaborative model of programming over a three-year timeframe via a series of three month-long student clinical rotations at the organization's two locations. The length of each occupational therapy clinical student rotation spanned a total of 12 weeks as mandated by occupational therapy education accreditation requirements [31]. Occupational therapy services available to participants within this program were provided through a collaborative occupational therapist/student fieldwork model for community interventions and within a recovery model approach supported by the Substance Abuse and Mental Health Services Administration (SAMHSA) [32, 33].

Programing included interventions geared toward mental health promotion, well-being, and improvement of an individual's overall quality of life. Occupational therapy services were delivered in a variety of formats depending upon the specific needs identified through the screening process. Services were provided through brief consultative (as needed) sessions, one-to-one 45-minute treatment sessions (2-3 times a week) and/or a 45-min group-based treatment session (1-2 times a week). Participants were not seen in occupational therapy more than 2 to 3 times a week as students alternated their services 5 days a week between both locations.

Participants initiated the occupational therapy process at both locations either by self or administrative referral; all voluntarily agreed to participate. Depending on participants' expressed need, individual interventions ranged from collaborating on the identification and use of positive coping strategies, developing healthy habits and routines, dealing with addiction, anger and stress management strategies, medication management, identification of housing and employment opportunities, GED education access and training, increasing awareness of community support resources, and money and time management. Group topics ranged from personal hygiene, mental and physical health education, return-to-work skills, sleep hygiene, stress and anger management, meal planning on a budget, Spanglish in the community, and effective communication/teamwork at home and in the workplace. Intervention timeframes ranged from 2 to 10 weeks in light of the 12 -week student clinical rotation timeline described above. Weeks 1 and 2 consisted of screening, evaluation, treatment planning and goal setting with each participant. Weeks 3 through 10 involved active engagement in occupational therapy intervention services, and weeks 11 and 12 involved formal discharge evaluation and planning for each participant.

Prior to the initiation of services, a nine-question Occupational Therapy Preliminary Screening Tool was used to obtain each participant's desired area of focus. This semi-structured interview tool was administered one-on-one by a student on a three-point scale 
("yes," "somewhat," or "no") [34]. Screening tool questions were constructed to elicit client profile information related to current and future work and education aspirations, budgeting, leisure participation, sleep hygiene, diet and exercise strategies, stress and anger management techniques, self-efficacy, problem solving strategies, and overall sense of pride. Reliability or validity has not been determined for this screening tool.

Using a client-centered approach, each participant collaborated with the occupational therapist and/or occupational therapy students during screening as to what type of intervention approach was most appropriate (i.e., individual only, group only, or individual and group). Participants that demonstrated and/or identified a need for individual occupational therapy intervention were then evaluated with the Canadian Occupational Performance Measure (COPM). The COPM is a standardized client-centered outcome measure that facilitates goal identification and captures change in set goals during treatment [35]. The semi-structured interview format of the COPM was selected as the instrument of choice, as the tool primarily focuses upon what the participant "wants, needs, or is expected to do" [35, p. 4]. Based on the results of the COPM, a full treatment plan that included measurable goals was then developed, reviewed and approved by the participant. The final step of the occupational therapy process involved participant reassessment via the COPM which occurred just prior to termination of services during weeks 11 and 12. Research indicates the COPM is considered most useful when administered to a participant at the beginning of services and at various points during intervention to measure progress [35]. The COPM demonstrates good divergent and convergent validity [36].

\section{Sample}

This retrospective analysis included 44 participants ( $n=44 ; 18$ males and 26 females) who completed initial and reassessment COPM semi-structured interviews within a 10 -week or less timeframe. Demographics and participation in occupational therapy services are described in Table 1 . Since this setting is a work rehabilitation setting, individual and specific SMI diagnostic demographic information was not readily available for many of participants in this analysis. Available demographic data was collected through participant record review and through participant self-report. Participant files were de-identified based upon completion of the COPM pre/post occupational therapy services. Participants who had received occupational therapy intervention services but were not reassessed at (post) discharge were not included in this retrospective analysis. This retrospective review was approved by the authors' University Institutional Review Board (IRB) which also required each author to indicate conflicts of interest related to this study. No conflicts were identified and all authors certify responsibility for the content of this study.

\section{Results}

The statistical software package SPSS Version 23 (SPSS Inc.) was used for all data analyses. Narrative participant responses captured at discharge from occupational therapy services were also integrated with the descriptive statistics to create a full picture of the programmatic evaluation.

A paired samples $t$ test showed that there was a significant increase in both COPM satisfaction, $\mathrm{t}(43)=-11.16, p<.05, d=1.94$; and COPM performance $\mathrm{t}(43)=-10.32, p<.05, d=1.79$, from initial (pre) to reassessment (post). Cohen's d was computed and the effect size for both satisfaction and performance were large $(d=1.79-1.94)$. Findings are shown in Table 2.

Reassessment (post) performance overall score as measured on the COPM was highly correlated with reassessment satisfaction overall score $(r=.88$, $p<.00)$ and is shown in Fig. 1.

Results showed that the occupational therapy interventions had a positive impact on participant perceived satisfaction and performance with the identified area of need indicated at the start of services in no more than a 10 -week time period that included no more than 2-3 individual sessions a week for 45 min. Length (number of weeks) of intervention did not show a significant relationship for performance or satisfaction. Individuals who reported high satisfaction also reported high performance on the areas identified in the COPM at reassessment. Occupational therapy interventions for participants' identified area of need is provided in Table 3 . 
Table 1 Demographics and participation in occupational therapy services

\begin{tabular}{llllll}
\hline Gender & $n(\%)$ & Age mean (SD) & $\begin{array}{l}\text { Total \# of } \\
1: 1 \text { Visits mean (SD) }\end{array}$ & $\begin{array}{l}\text { Total duration (time) } \\
\text { Attended mean (SD) }\end{array}$ & $\begin{array}{l}\text { Treatment } \\
\text { Days mean (SD) }\end{array}$ \\
\hline Male & $18(41)$ & $37.95(18.23)$ & $12.28(3.92)$ & $7.06(5.24)$ & $57.00(8.94)$ \\
Female & $26(59)$ & $41.05(13.16)$ & $13.00(3.94)$ & $6.12(5.32)$ & $54.81(10.97)$ \\
Total & $44(100)$ & $39.78(15.32)$ & $12.70(3.90)$ & $6.50(5.25)$ & $55.70(10.14)$ \\
\hline
\end{tabular}

Table 2 COPM performance and satisfaction scores pre-post assessment

\begin{tabular}{lllllll}
\hline COPM categories & Pre mean (SD) & Post mean (SD) & Mean change & $t(d f)$ & sig & Effect size \\
\hline Satisfaction $(n=44)$ & 3.36 & & 3.51 & - & $11.16(43)$ & .000 \\
& $(1.91)$ & $6.84(1.67)$ & & -2.65 & 1.94 \\
Performance $(n=44)$ & 4.14 & & & $10.32(43)$ & .000 \\
\hline
\end{tabular}

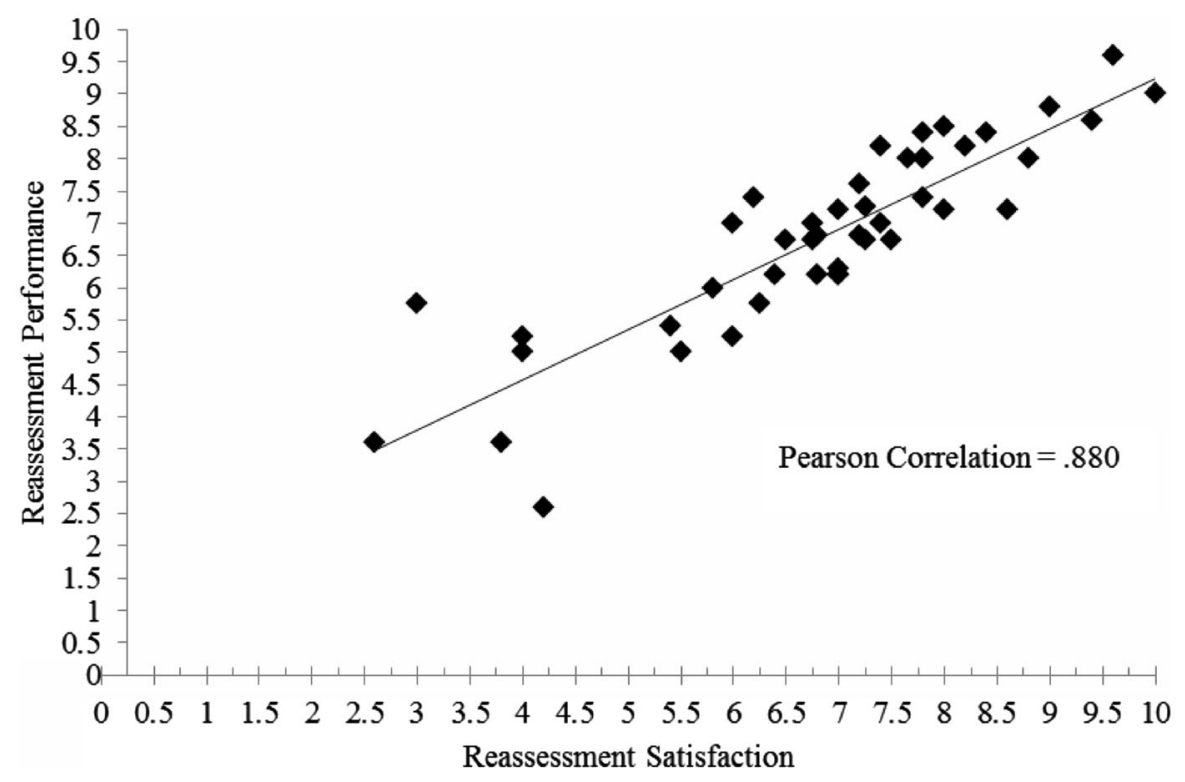

Fig. 1 COPM post satisfaction and performance correlation reassessment (post) performance overall score as measured on the COPM was highly correlated with reassessment satisfaction overall score $(r=.88, p<.00)$ and is shown in Fig. 1

Participants provided narrative responses to the impact of occupational therapy intervention at the time of discharge. Direct quote responses relate to the most highly-identified occupation areas related to the COPM domains of self-care, leisure, and productivity. One participant stated, "Before I came to occupational therapy, I was in the storm. Occupational therapy is like my umbrella. Even though it is still raining, I am able to walk through it;" another participant communicated that through occupational therapy, "I learned to motivate myself... and to believe in myself..." and that "my money management skills have improved and that I am independently managing weekly paychecks." Another participant noted, "Occupational therapy has helped me with self-motivation... and has motivated me to sign-up for classes." At 
Table 3 Occupational therapy intervention for participant identified area of need

\begin{tabular}{|c|c|c|}
\hline $\begin{array}{l}\text { COPM } \\
\text { domain }\end{array}$ & OT intervention & $\begin{array}{l}\text { Prevalence of area } \\
\text { of need* }\end{array}$ \\
\hline \multirow[t]{6}{*}{ Productivity } & Work & $38(19 \%)$ \\
\hline & $\begin{array}{l}\text { Exploring and pursuing realistic employment, resume writing, interviewing (mock interviews } \\
\& \text { feedback), computer skill training, effective worksite communication and general literacy } \\
\text { assessment/intervention }\end{array}$ & \\
\hline & Education & $27(14 \%)$ \\
\hline & $\begin{array}{l}\text { Obtaining funding for GED test preparation, registering for night classes, improving math, } \\
\text { writing, reading, and computer skills, applying to college, referrals for tutoring and } \\
\text { community academic support services }\end{array}$ & \\
\hline & Productivity (general) & $12(7 \%)$ \\
\hline & $\begin{array}{l}\text { Obtaining expungement, workspace and environmental adaptations (seating, lighting, desk } \\
\text { organization), improving attention, using visual/verbal cueing aids, coping strategies for } \\
\text { stress and/or money management, cooking on a budget }\end{array}$ & \\
\hline \multirow[t]{10}{*}{ Leisure } & Psychological Management & $31(16 \%)$ \\
\hline & $\begin{array}{l}\text { DSM-V diagnosis education and medication management, referral to counseling, addiction/ } \\
\text { trigger identification, relapse prevention, WRAP (wellness recovery action planning), self- } \\
\text { talk and visualization strategies, coping with auditory hallucinations, strategies to manage } \\
\text { anger, stress, depression, grief, and anxiety }\end{array}$ & \\
\hline & Leisure Exploration and Participation & $14(7 \%)$ \\
\hline & $\begin{array}{l}\text { Development of healthy leisure activities, restorative hobbies (joining a ceramics group, } \\
\text { swimming, journaling, book club participation, use of pedometer via a walking club) }\end{array}$ & \\
\hline & Social Participation & $12(6 \%)$ \\
\hline & $\begin{array}{l}\text { Reconnecting with friends and family, planning healthy social activities, developing new } \\
\text { friendships post incarceration, handling holiday stress }\end{array}$ & \\
\hline & Leisure (Miscellaneous) & $12(6 \%)$ \\
\hline & $\begin{array}{l}\text { Development of new activities (exercise, baking, volunteering), accessing social media, finding } \\
\text { a place of worship, and obtaining a cell phone }\end{array}$ & \\
\hline & Health Maintenance and Management & $8(4 \%)$ \\
\hline & $\begin{array}{l}\text { Sleeping, exercising, healthy eating, life balance, setting boundaries, crisis management, } \\
\text { suicide ideation management and prevention education }\end{array}$ & \\
\hline \multirow[t]{8}{*}{ Self-care } & Financial Management & $19(10 \%)$ \\
\hline & $\begin{array}{l}\text { Budgeting, paying bills, filing taxes, opening a savings/checking account, creating a realistic } \\
\text { budget, meal planning on a budget, understanding a paycheck stub, identifying a housing } \\
\text { option based on income, understanding social security disability }\end{array}$ & \\
\hline & Health Maintenance and Management & $9(5 \%)$ \\
\hline & $\begin{array}{l}\text { Sleep, stress, health, pain management, smoking cessation, exercise, developing healthy } \\
\text { hygiene and appearance, sexual education, addressing impact of co-morbidities (managing } \\
\text { hypertension, diabetes), harm reduction strategies for drug and alcohol use, and weight } \\
\text { management }\end{array}$ & \\
\hline & Self-Care (Miscellaneous) & $9(5 \%)$ \\
\hline & $\begin{array}{l}\text { Increasing confidence, improving memory and attention, dressing on a budget, appropriate } \\
\text { dress in the workplace, hair care, accessing dental care, parent training re: typical childhood } \\
\text { development, education, and discipline strategies }\end{array}$ & \\
\hline & Driving and Community Mobility & $5(3 \%)$ \\
\hline & $\begin{array}{l}\text { Preparation for obtaining a driver's license, utilizing public transportation, safety awareness in } \\
\text { the community, identifying and connecting with community resources }\end{array}$ & \\
\hline
\end{tabular}

*196 total problems identified in $(\mathrm{n}=44)$ COPM assessments

Theoretical/Model/Framework basis to support array of interventions listed: Cognitive Behavioral Model: Beck, 2011; Transtheoretical Model: Prochaska and DiClemente 1983; Person-Environment-Occupational Model:Law et al. 1996; Model of Human Occupation: Keilhofner 2008; Recovery and Harm Reduction Approaches: SAMHSA 2012 
discharge, another participant reported, "Occupational therapy has helped me communicate and work better with others..." also stating that, "I learned about careers to look at for the future." Responses highly suggest that participants had positive experiences regardless of the intervention area in which goals were focused.

\section{Discussion}

Clarity surrounding demographic diagnostic breakup was incomplete on all records and limited to participant self-report. Schizoaffective disorder, schizophrenia, bipolar disorder, major depressive disorder, substance use disorder, anxiety, PTSD, trauma, a previous history of homelessness or incarceration was identified for some, but was not available on all participant records analyzed. Many participants who received individual occupational therapy services also participated in weekly onsite occupational therapy group programming in the areas of mental health and wellness, stress and anger management, money management, assertiveness training, vocational skill development and more. Since this retrospective analysis was limited to participants who completed pre/post COPM assessment only, the researchers were unable to compare the effectiveness of group only versus individual occupational therapy intervention.

Findings indicate that the positive change scores captured with the COPM may have also been influenced by group occupational therapy programming. While the COPM is considered a reliable and valid tool for pre/post scoring, the essence of occupational therapy treatment is based in a client-centered and individualistic approach. For example, identified under the COPM domain of "productivity" out of 196 total problems identified by participants, 38 (or $19 \%$ ) of those problems related to the area of "work" (see Table 3). Each occupational therapy intervention approach that addressed "work" was tailored to the specific individual. One participant identified the need to explore realistic employment; another desired to increase computer skill training, while another noted the need to learn effective work site communication. Individualized and client-centered approaches to treatment are unique to occupational therapy, but can present as a limitation, as deductive groupings for clear delineation between specific interventions administered per COPM category in the areas of self-care, productivity, and leisure are not rote, and all determined goals are open-ended and tailored to the individual.

It is noteworthy that participants with a history of SMI, homelessness and/or individuals with ex-offending histories demonstrated statistically significant improvement via the COPM. The outcomes indicate the impact of individualized occupational therapy interventions in a relatively short time frame, suggesting the power of occupational therapy and the effectiveness from implementation of brief, but meaningful, occupation-based interventions in the community [37]. Although this retrospective analysis focused on services provided within one program, outcomes suggest individualized occupational therapy intervention provides significant benefits for individuals with behavioral and/or mental health, wellness, and employment needs. Occupational therapists are trained to develop client-centered occupational therapy consultative, individual and group programming using collaborative, evidence and theory-based models, including the recovery model as noted in the Occupational Therapy Practice Framework to support needs within the community [38]. Findings from this retrospective analysis warrant consideration for expanding the role of occupational therapists to include consultant, employment specialist, and/or program director and recognition as qualified mental health service providers in Certified Community Behavioral Health Clinics (CCBHCs) [39]. Replication of this occupational therapy program model may further enhance the delivery of individualized interventions within other community based behavioral and/or mental health settings in order to meet the needs of individuals, groups and/or populations of individuals with mild intellectual disabilities, SMI, homelessness and/or with a history of incarceration in order to facilitate satisfaction and performance in daily life.

Acknowledgement The authors would like to thank Bernadette Alpajora, Michael Barrett, and the occupational therapy fieldwork students who participated in this programming for their gracious contributions toward this project.

\section{Compliance with Ethical Standards}

The submitted manuscript was approved by the authors' University Institutional Review (IRB). This process required each author to indicate all potential conflicts of interest related to this study. No conflicts were identified and all authors certify 
responsibility for the content of this manuscript. All authors also certify that there are no conflicts of interests in relation to the requirements indicated on the journal's website. All authors' have adhered to the required "ethical responsibilities of authors" required for the submission of this manuscript and have signed and submitted conflict of interest forms. This project is unfunded.

Open Access This article is distributed under the terms of the Creative Commons Attribution 4.0 International License (http:// creativecommons.org/licenses/by/4.0/), which permits unrestricted use, distribution, and reproduction in any medium, provided you give appropriate credit to the original author(s) and the source, provide a link to the Creative Commons license, and indicate if changes were made.

\section{References}

1. World Health Organization. Mental Disorders. https:// www.who.int/mediacentre/factsheets/fs396/en/. Published April 9, 2018.

2. Mental illness facts and numbers. NAMI: National Alliance on Mental Illness. https://www.nami.org/factsheets/ mentalillness_factsheet.pdf, https://www.nami.org/LearnMore/Mental-Health-By-the-Numbers. Published 2013.

3. Jailing people with mental illness. NAMI: National Alliance on Mental Illness. https://www.nami.org/Learn-More/ Public-Policy/Jailing-People-with-Mental-Illness. Published 2018.

4. Access to mental health care and incarceration. Mental Health America. https://www.mentalhealthamerica.net/ issues/access-mental-health-care-and-incarceration. Published 2018.

5. van Olphen J, Freudenberg N, Fortin P, Galea S. Community reentry: perceptions of people with substance use problems returning home from New York City jails. J Urban Health. 2006;83(3):372-81. https://doi.org/10.1007/s11524-0069047-4.

6. American Occupational Therapy Association [AOTA]. Mental Health. https://www.aota.org/Practice/MentalHealth.aspx. Updated 2016.

7. Mee J, Sumsion T. Mental health clients confirm the motivating power of occupation. Br J Occup Ther. 2001;64:121-8. https://doi.org/10.1177/030802260106400303.

8. American Occupational Therapy Association [AOTA]. Specialized knowledge and skills in mental health promotion, prevention, and intervention in occupational therapy practice. Am J Occup Ther. 2010; 64:s30-s43. https://doi. org/10.5014/ajot.2010.64s30.

9. Auerbach ES. The individual placement and support model versus the menu approach to supported employment. Occup Ther Ment Health. 2002;17(2):1-19. https://doi.org/10. 1300/j004v17n02_01.

10. Swarbrick M, Noyes S. Effectiveness of occupational therapy services in mental health practice. American Journal of Occupational Therapy. 2018. https://doi.org/10.5014/ ajot.2018.725001.

11. D’Amico ML, Jaffe LE, Gardner JA. Evidence for interventions to improve and maintain occupational performance and participation for people with serious mental illness: a systematic review. Am J Occup Ther. 2018. https://doi.org/ 10.5014/ajot.2018.033332.

12. Gibson RW, Damico M, Jaffe L, Arbesman M. Occupational therapy interventions for recovery in the areas of community integration and normative life roles for adults with serious mental illness: a systematic review. Am J Occup Ther. 2011;65(3):247-56. https://doi.org/10.5014/ ajot.2011.001297.

13. Peloquin PM, Ciro CA. Population-centered life skills groups: perceptions of satisfaction and engagement. Am J Occup Ther. 2013;67(5):594-600. https://doi.org/10.5014/ ajot.2014.008425.

14. Hyett N, McKinstry CE, Kenny A, Dickson-Swift V. Community-centered practice: occupational therapists improving the health and wellbeing of populations. Aust Occup Ther J. 2015;63:5-8. https://doi.org/10.1111/14401630.12222.

15. Doroud N, Fossey E, Fortune T. Recovery as an occupational journey: a scoping review exploring the links between occupational engagement and recovery for people with enduring mental health issues. Aust Occup Ther J. 2015;62(6):378-92. https://doi.org/10.1111/1440-1630. 12238 .

16. Scaffa ME, Reitz SM. Occupational therapy in communitybased practice settings. Philadelphia, PA: F.A. Davis \& Company; 2014.

17. Williams AE, Fossey E, Corbiere M, Paluch T, Harvey C. Work participation for people with severe mental illnesses: an integrative review of factors impacting job tenure. Aust Occup Ther J. 2016;63(2):65-85. https://doi.org/10.1111/ 1440-1630.12237.

18. Frounfelker RL, Glover CM, Teachout A, Wilkniss SM, Whitley R. Access to supported employment for consumers with criminal justice involvement. Psychiatr Rehabil J. 2010;34(1):49-56. https://doi.org/10.2975/34.1.2010.49.56.

19. Mueser KT, Drake RE, Bond GR. Recent advances in supported employment for people with serious mental illness. Curr Opin Psychiatr. 2016;29(3):196-201. https://doi. org/10.1097/yco.0000000000000247.

20. Rosenheck R, Mueser KT, Sint K, et al. Supported employment and education in comprehensive, integrated care for first episode psychosis: effects on work, school, and disability income. Schizophr Res. 2017;182:120-8. https:// doi.org/10.1016/j.schres.2016.09.024.

21. Corbière M, Lecomte T, Reinharz D, et al. Predictors of acquisition of competitive employment for people enrolled in supported employment programs. J Nerv Ment Dis. 2017;205(4):275-82. https://doi.org/10.1097/nmd. 0000000000000612.

22. Metcalfe JD, Riley J, Mcgurk S, Hale T, Drake RE, Bond GR. Comparing predictors of employment in individual placement and support: a longitudinal analysis. Psychiatry Res. 2018;264:85-90. https://doi.org/10.1016/j.psychres. 2018.03.050.

23. Doroud N, Fossey E, Fortune T. Recovery as an occupational journey: a scoping review exploring the links between occupational engagement and recovery for people with enduring mental health issues. Aust Occup Ther J. 2015;62(6):378-92. https://doi.org/10.1111/1440-1630. 12238. 
24. Schindler VP, Sauerwald C. Outcomes of a 4-year program with higher education and employment goals for individuals diagnosed with mental illness. Occup Ther Ment Health. 2013;46(3):325-36. https://doi.org/10.1080/0164212x. 2017.1419900.

25. Noyes S, Sokolow H, Arbesman M. Evidence for occupational therapy intervention with employment and education for adults with serious mental Illness: a systematic review. Am J Occup Ther. 2018;72(5):1-2. https://doi.org/10.5014/ ajot.2018.033068.

26. Lee H-L, Hwang EJ, Wu S-L, Tu W-M, Wang MH, Chan F. Employment outcomes after vocational training for people with chronic psychiatric disorders: a multicenter study. Am J Occup Ther. 2018. https://doi.org/10.5014/ajot.2018. 028621.

27. Smith DL, Atmatzidis K, Capogreco M, Lloyd-Randolfi D, Seman V. Evidence-based interventions for increasing work participation for persons with various disabilities. OTJR. 2017. https://doi.org/10.1177/1539449216681276.

28. Stelter L, Whisner SM. Building responsibility for self through meaningful roles. Occup Ther Ment Health. 2007;23(1):69-84. https://doi.org/10.1300/j004v23n01_05.

29. Valencia M, Rascon ML, Juarez F, Murow E. A psychosocial skills training approach in Mexican out-patients with schizophrenia. Psychol Med. 2007;37(10):1393-402. https://doi.org/10.1017/S0033291707000657.

30. Bartels SJ, Forester B, Mueser KT, et al. Enhanced skill training and health care management for older persons with severe illness. Community Ment Health J. 2004;2004(40): 75-90.

31. Accreditation council for occupational therapy education (ACOTE) standards and interpretive guide (2018) American Occupational Therapy Association. https://www.aota. org/ /media/Corporate/Files/EducationCareers/Accredit/
StandardsReview/2018-ACOTE-Standards-InterpretiveGuide.pdf.

32. Hanson DJ, Deluliis ED. The collaborative model of fieldwork education: a blueprint for group supervision of students. Occup Ther Health Care. 2015;29(2):223-39. https:// doi.org/10.3109/07380577.2015.1011297.

33. Substance Abuse and Mental Health Services Administration [SAMHSA]. Recovery and recovery support. http:// www.samhsa.gov/recovery. Updated September 20, 2017.

34. DeAngelis T. Occupational therapy preliminary screening tool. Philadelphia, PA: Thomas Jefferson University; 2013.

35. Law M, Baptiste S, Carswell A, McColl MA, Polatajko H, Pollock N. The Canadian occupational performance measure. 5th ed. Ottawa: Canadian Association of Occupational Therapists; 2014.

36. Dedding C, Cardol M, Eyssen ICJ, Beelen A. Validity of the Canadian occupational performance measure: a client-centered outcome measurement. Clin Rehabil. 2004;18(6): 660-7. https://doi.org/10.1191/0269215504cr746oa.

37. Brown S, Chan K. A randomized controlled trial of a brief health promotion intervention in a population with serious mental illness. J Ment Health. 2009; 15:543-9. https://doi. org/10.1080/09638230600902609.

38. American Occupational Therapy Association [AOTA]. Occupational therapy practice framework: domain and process, 3rd ed. AJOT 2014; 60:s1-s48. https://doi.org/10. 5014/ajot.2014.682006.

39. Scaffa ME, Reitz SM. Occupational therapy in communitybased practice settings. Philadelphia: F.A. Davis Company; 2014.

Publisher's Note Springer Nature remains neutral with regard to jurisdictional claims in published maps and institutional affiliations. 